\title{
Knowledge, Attitude and Behavior on Overweight and Obesity, Health Consequence and Adaptation to Lifestyle Changes among Early Middle Age Medical and Non-medical Health Care Staffs of NMC Day Care Centre, Abu Dhabi, UAE
}

\author{
Article by Anette Marina Rodrigues \\ $B S c, R N$, Texila American University \\ E-mail: annsweety39@gmail.com
}

\begin{abstract}
This non-experimental descriptive cross-sectional survey explored the knowledge, attitude and behavior (KAB Survey) related to overweight and obesity its health consequence and ways to manage ideal body image and balanced weight with diet, exercise and lifestyle modification among medical and non-medical staffs belonging to origin Indian, Nepalese, Middle east and Philippines of NMC day care center, AL wadi, Abu Dhabi, UAE.

Design and procedure: A non-experimental descriptive Random cross section study was conducted among (30) medical and non-medical staffs out of 120, who have joined the team for over a period of 1.5 to 2 years since 2014. Two months convenient sampling was done using Semi-structured questionnaire. Qualitative and quantitative data analyzed through Content analysis and Health Behavior Knowledge Scale.15 questions, including open ended Questions, choose correct answer from four options and fill in the blanks was used as method to assess Health and Behavior Knowledge.

Results: The findings showed that Random Sampling of 30 Staffs, from 2014 and who stayed in UAE. $73.3 \%$ had normal BMI, 23.3\% fall under Overweight, and 3.3\% fall under Obesity. In 2016, the result showed $36.6 \%$ have normal, 46.6\% Overweight, $10 \%$ Obese. The results of knowledge on diet were as follows $-73.3 \%$ had adequate information on diet and $26.6 \%$ lacked information on diet, whereas the attitude towards Overweight and Obesity, $66.6 \%$ were aware on negative health consequence and ways to handle them. With the knowledge on diet, $86.6 \%$ have adequate information on diet and $13.3 \%$ still have misconception on diet, whereas the attitude towards Overweight and Obesity was remarkable 100\% were aware on negative health consequence and ways to handle them

The vast significance which was alarming was in area of exercise.33.3\% had positive attitude towards exercise and $66.6 \%$ had negative attitude towards exercise. After training on Exercise for 1 month, results are as, $83.3 \%$ have positive attitude towards exercise, $13.3 \%$ have reduced weight and gained muscle strength through exercise and $16.6 \%$ have still misunderstood about concept of exercise.

The body Image Tool parameter results as follows using 9 figures, black and white of male and female, the current body image value is minimum shape of $4(n=7), 5(n=7), 6(n=9), 7(n=3)$ to maximum shape 8 $(n=1)$ and ideal body image minimum shape individuals want to attain,4(n=15), 5(n=6), to maximum shape $6(n=1)$, neutral $(n=1)$

Conclusion: The study reveals that individual have interest to follow correct pattern of diet, exercise and maintain their body image and control Overweight and Obesity, with minimum exercise of 30 minutes to lhour every three days in a week. One more point comes into consideration is $\underline{H}$ w to go about to attain measurable values to ideal Body weight and Image as long term goal.
\end{abstract}

Keywords: Knowledge, Attitude, Behavior, Lifestyle, Diet, Exercise, Body Image

\section{Introduction}

The purpose of study is determine the extent of knowledge, attitude and behavior on Overweight and Obesity, health consequence and ways to adapt to lifestyle changes among medical and non-medical staffs of my facility. 
DOI: $10.21522 /$ TIJNR.2015.03.02.Art018

ISSN: $2520-3126$

1. Identify total number of staff, fall under category of overweight and obesity.

2. Assess the knowledge on type of diet including $24 \mathrm{hrs}$. Menu.

3. Assess the behavior on prevention of health risk consequence before and after pre-and post, Semi Structured Questionnaire and Health Behavior Knowledge Scale.

4. Identify the effect of health education (leaflets) on exercise and adapt changes of lifestyle to give time for exercise, few hours every week.

5. Identify attitude of the staff to personal present body image and ideal body image

The target group identified is between age group of 23 to 35 years. The problem identified within two years is that Overweight and Obesity is gradually increasing and need to adapt lifestyle changes like diet control and exercise to reduce the Overweight and Obesity, to avoid health consequence in later years.

The existing solution is to provide adequate Knowledge on Healthy Diet, Exercises and identify the changes in attitude and behavior on balanced diet, exercise and lifestyle changes. The best solution would be spare 1 hour of time every alternate day to do Exercise and avoid unhealthy food, limit calories to 1500 in a day by following Diet Meal Plan for 24 hours. Limitation is long duty hours, late shifts and time constrains.

In order to be successful in following the plan, provide adequate Knowledge through PPT and Printouts on health-related effects of Overweight and Obesity like early CVS, Hypertension and Diabetes Mellitus. And have an adequate positive change in behavior and attitude of Staffs towards Overweight, Obesity and Health Consequence and adapt lifestyle changes in order to maintain their body Physique as they have imagined.

\section{Methods}

A non-experimental descriptive cross section study was done on 30 medical and non -medical staffs. Staffs were selected on basis of their stay in UAE for more than 18 months. The staffs' age more than 36 years were exempted from the research.

The KAB survey reveals the knowledge, attitude and behavior related to diet, exercise, health consequence related to overweight and obesity and misconception and misunderstanding that I would like to implement and potential barriers to behavior changes.

Consent was taken from the management and participants before starting the study.

Anthropometric and Demographics study including age, job class, education level and working hours. All participants fall within age group of 23 to 35 years, early middle age. (Figure -1). Observation method was used to assess the physical appearance of individuals, non-biased random selection with unstructured pretest and posttest Questionnaire and PPT was used with time frame of 1 months.

Body Image was assessed using the Body Image Assessment Methodology (Figure- 1A). Staffs were given card with black and white line drawn image of 9 male and female ranging from very thin to very Obese. Staffs were asked to indicate which drawing most resembled their current figure (current body size) and the figure they wished most to resemble (ideal body image), a high score indicate larger body size. A body diaspora score was derived from the discrepancy between current and ideal figures. A high score indicates greater discrepancy between ideal and current body size. (Ref-2).

Body Image tool-(Figure- 1A). 

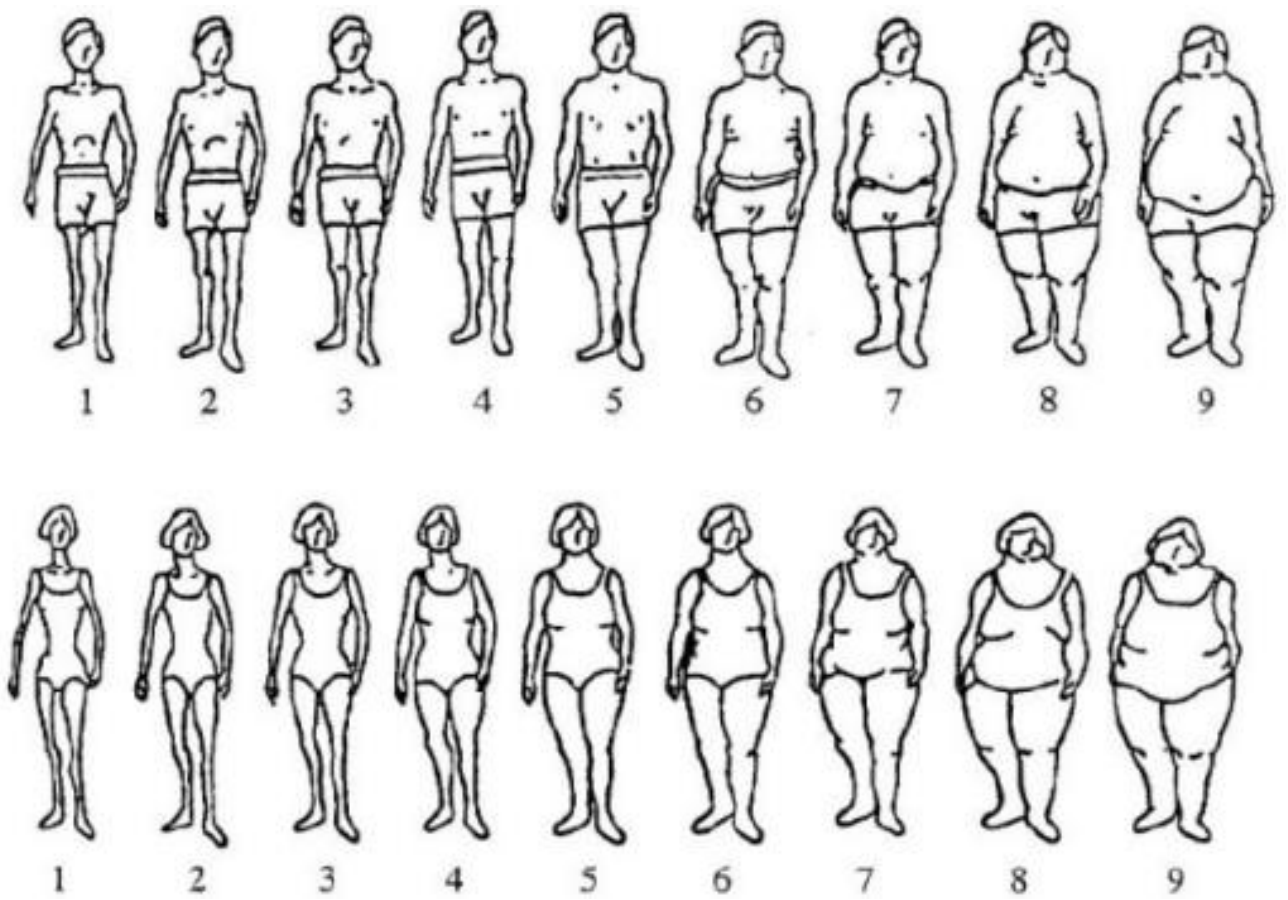

Health Behavior knowledge, physical activity knowledge and Balanced diet was done using power point presentation and handouts.

\section{Result}

The bar graph (Figure-2) represents the difference of BMI among different individual from different countries who live and work in UAE from past 1.5 to 2 years. The findings show that Random Sample of 30 Staffs, worked from 2014 work and stay in UAE 73.3\% had normal BMI, 23.3\% fall under Overweight, and $3.3 \%$ fall under Obesity. In 2016, currently 36.6\% have normal, 46.6\% Overweight, $10 \%$ Obese.

The results of knowledge on diet as follows $73.3 \%$ had adequate information on diet and $26.6 \%$ lacked information on diet (Figure-3A). After training on Diet for 1 month, results are as follows the knowledge on diet , 86.6\% have adequate information on diet and $13.3 \%$ still have misconception on diet. (Figure-3B). The result shows that staffs had adequate knowledge on health information, but did not have correct information on ill health and type of diseases like Hypertension, Diabetic Mellitus and Cardiovascular diseases which Intern may come earlier in life due to overweight and obesity.

The introduction of diet plan (Ref-1), vegetarian and non-vegetarian, depending on their choices, a diet plan for 24 hours was given. Individuals were given time period of one month to decide, adapt and implement. In the post assessment, I got positive results saying $10.6 \%$ increase in following the diet pattern and have decided and planned to adopt the desired calorie and type of food to be introduced into daily diet through pretest and posttest Questionnaire.

However, the vast significance which was alarming was only $33.3 \%$ had positive attitude towards exercise and $66.6 \%$ had negative attitude towards exercise (Figure-4A), after the information provided on exercise $83.3 \%$ have positive attitude towards exercise, $13.3 \%$ have reduced weight and gained muscle strength through exercise and $16.6 \%$ have still misunderstood about concept of exercise (Figure-4B). Knowledge on exercise, type of exercise like Zumba, walking, jogging, Aerobics, Cycling, Gym, Outdoor games and activities, advantages and disadvantages, type of exercise suitable for adjustment to duty hours and type of ergonomics to be used in hospital. After information on exercise there was $50 \%$ increase from pretest, in the individuals who were ready to adopt to follow in their routine, three times a week, at least 30 minutes of exercise and later increase depend on adjustment of time. 
DOI: $10.21522 /$ TIJNR.2015.03.02.Art018

ISSN: $2520-3126$

The body Image Tool parameter results as follows using 9 figures, black and white of male and female, the current body image value is minimum shape of $4(n=7), 5(n=7), 6(n=9), 7(n=3)$ to maximum shape 8 $(n=1)$ and ideal body image minimum shape individuals want to attain,4(n=15),5(n=6), to maximum shape $6(n=1)$, neutral $(n=1)$.(Figure-5). The concept of ideal body image had a great outcome require to be follow and maintain in long run. Right now staffs did not bother on body image due to work pressure and lack of time to follow diet and exercise, but ideal body image of 4 , shows about their thoughts to maintain balanced weight.

The attitude towards Overweight and Obesity was remarkable, $100 \%$ were aware on negative health consequence and ways to handle them and $80 \%$ of individuals had knowledge on health with their own past experiences and self-study and after the ppt presentation and posttest $100 \%$ individuals were able to gain adequate knowledge on health, diseases and its prevention the attitude towards Overweight and Obesity. (Figure-6).

\section{Discussion results comes first before discussion}

KAB Survey helped me to identify the need for change in knowledge, attitude and behavior of individual in short duration of time. The effectiveness of health teaching, teaching on diet, exercise and health consequence helped the individual a change their lifestyle and adapt to balanced health and nutrition.

The results have achieved target positive result in early middle aged individual who would adopt and have already started to adapt lifestyle changes in diet, health, exercise and body physique. It helps the management of health care to provide facilities like Yoga, Zumba and indoor Gym for the staffs and plans are going on for the same.

The results are in consistence to other researchers. Similar studies were conducted on Female Adolescents in Urban Philadelphia (Ref 3)-Use in-text citation instead

\section{Results}

Physical activity, inactivity and perception of ideal body size emerged as most important contributory factors to Obese Status. There was no statistically significant matched-pair difference in macro nutrient and micro nutrient intakes, self-esteem, eating attitudes, health behavior knowledge or maturation status of these individuals. Obese individuals had significantly lower levels of physical activity, higher inactivity and a larger perception of ideal body size than non-obese individuals.

\section{Discussion}

Knowledge and attitudinal factor (with exception of perception of ideal body size) had far less association with Obesity than activity related behavioral factors. These findings suggest that future intervention strategies should pay particular attention to physical activity, inactivity and body image attitudes.

Further question arise through my research findings is long term consistency in early middle age, in maintaining balanced health, lifestyle and exercise, balancing with work, stress and time and prevention of early entry of disease like Diabetic Mellitus, Hypertension and Cardio Vascular Diseases.

\section{Conclusion}

This study has helped staffs as health care members to take care of their health, diet and manage exercise as par to their work schedule in well balanced form. This will help them to follow regular routine, balance with work and time for self. They would plan out 30 minutes to 1 hour of exercise every three days in a week. This will have a positive effect on long term prevention of getting risk related diseases like Hypertension, Diabetes and Cardio vascular. The body Image parameters give an insight into oneself to

change one's lifestyle and maintain it. This research has helped staffs to think about the seriousness of one self, taking care of health and wellbeing. 


\section{Figures and tables}

Anthropometric and Demographic Study (Figure- 1)

\begin{tabular}{|c|c|c|}
\hline Content & & Percentage \\
\hline \multirow[t]{2}{*}{ Gender } & Male $(n=16)$ & $53.33 \%$ \\
\hline & Female $(n=14)$ & $46.66 \%$ \\
\hline Age & Years & $23-35$ \\
\hline Weight & Kilograms & $40-100+-5$ \\
\hline \multirow[t]{2}{*}{ BMI } & Male & $20-30.4+-4.4$ \\
\hline & Female & $15-25+-4.4$ \\
\hline \multirow[t]{4}{*}{ Country } & $\operatorname{Indian}(\mathrm{n}=18)$ & $60 \%$ \\
\hline & Nepalese $(n=4)$ & $13.3 \%$ \\
\hline & Middle East $(n=2)$ & $6.6 \%$ \\
\hline & Philippine $(\mathrm{n}=6)$ & $20 \%$ \\
\hline \multirow[t]{2}{*}{ Education } & Medical Staff $(n=14)$ & $46.6 \%$ \\
\hline & Non-Medical Staff $(n=16)$ & $53.3 \%$ \\
\hline \multirow[t]{4}{*}{ Job Class } & Registered Nurse $(\mathrm{n}=11)$ & $36.6 \%$ \\
\hline & Practical Nurse $(n=3)$ & $10 \%$ \\
\hline & $\begin{array}{l}\text { Front Office } \\
\text { Executives }(\mathrm{n}=8)\end{array}$ & $26.6 \%$ \\
\hline & messengers $(\mathrm{n}=8)$ & $26.6 \%$ \\
\hline \multirow[t]{4}{*}{ Years at NMC } & 0-6 months & Nil \\
\hline & 6-12 months & Nil \\
\hline & $13-16$ months $(\mathrm{n}=8)$ & $26.6 \%$ \\
\hline & 17-24 months $(\mathrm{n}=22)$ & $73.3 \%$ \\
\hline \multirow[t]{2}{*}{ Shift Hours } & $\begin{array}{l}\text { Split shift }(9: 00-21: 00) \\
\text { 4hrs break }(n=26)\end{array}$ & $86.6 \%$ \\
\hline & $\begin{array}{l}\text { Straight Shift }(9: 00-16: 30) \\
(n=4)\end{array}$ & $13.3 \%$ \\
\hline
\end{tabular}


DOI: $10.21522 /$ TIJNR.2015.03.02.Art018

ISSN: $2520-3126$

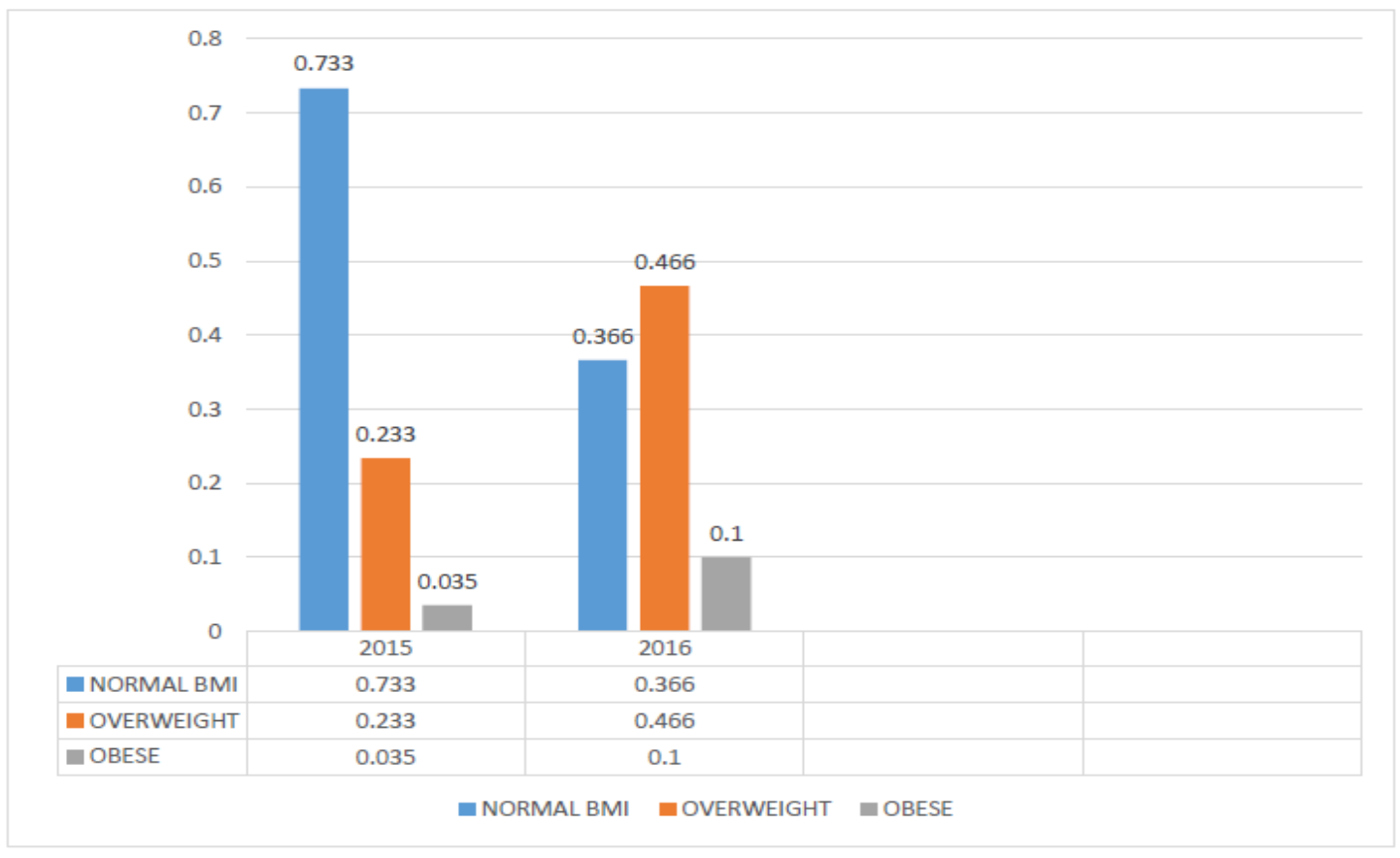

Figure 2. One year BMI statistics of individuals

\section{KNOWLEDGE ON DIET-PRETEST-Figure- 3A}

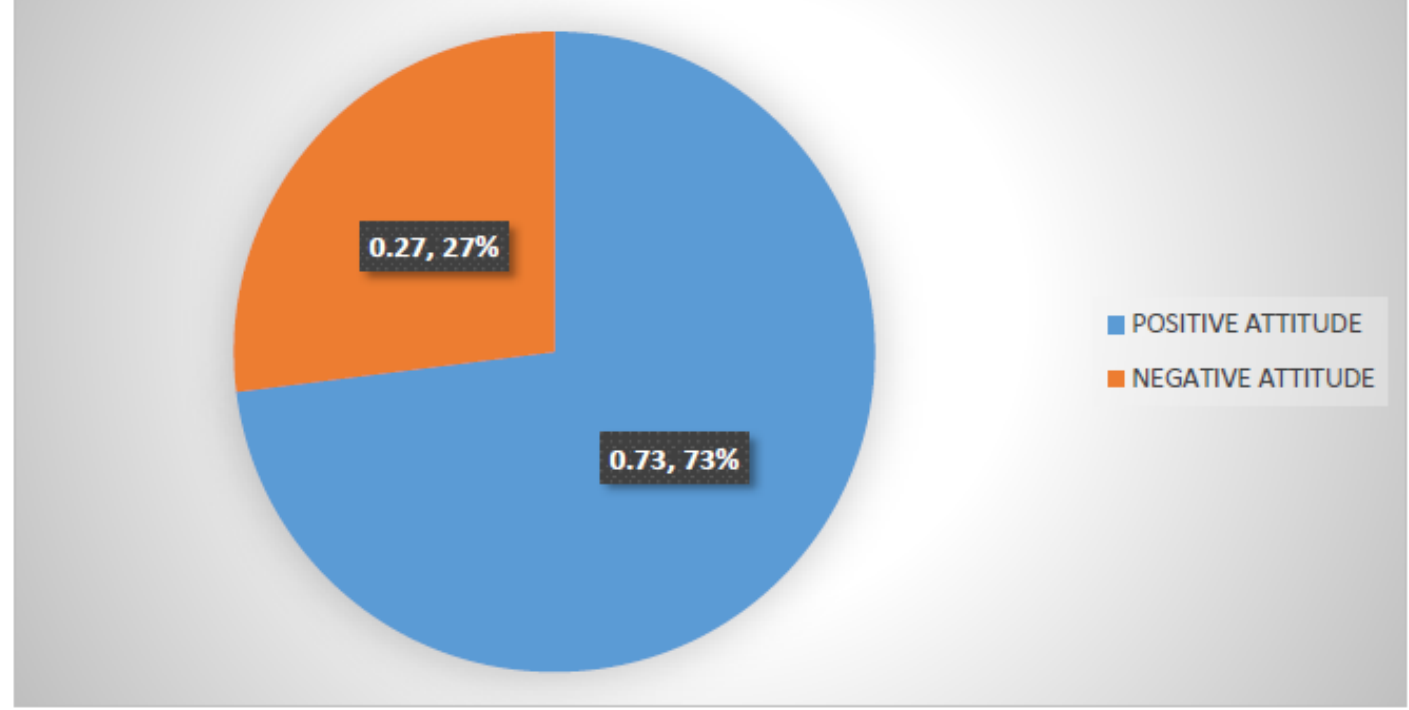

Figure 3a. Use instead here 


\section{KNOWLEDGE ON DIET-POST TEST Figure -3B}

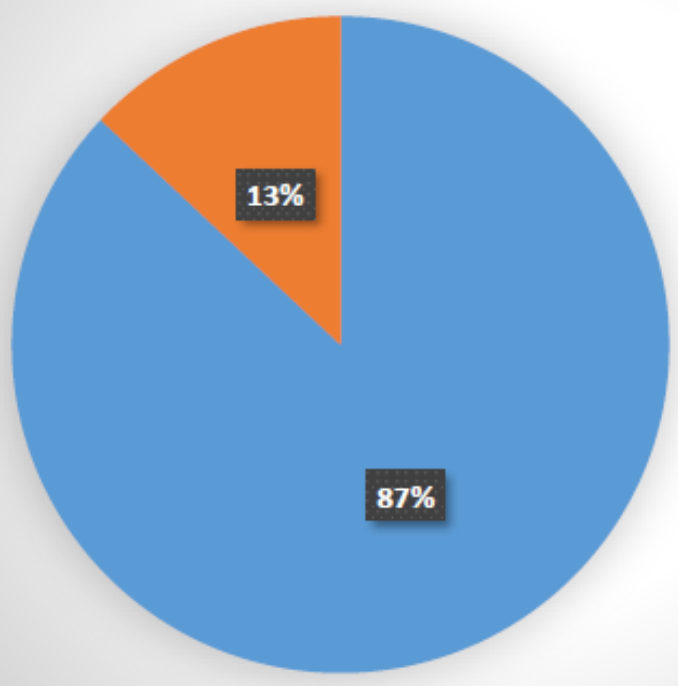

口 POSITIVE ATTITUDE

nEGATIVE ATTITUDE

\section{KNOWLEDGE ON EXERCISE-PRETEST Figure- 4A}

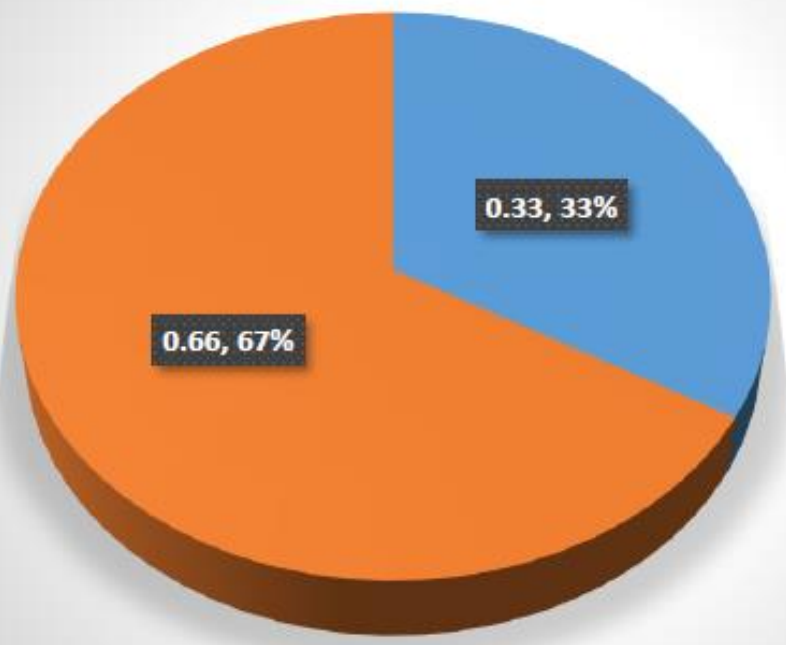

- POSITIVE

- LACKING 
DOI: $10.21522 /$ TIJNR.2015.03.02.Art018

ISSN: $2520-3126$
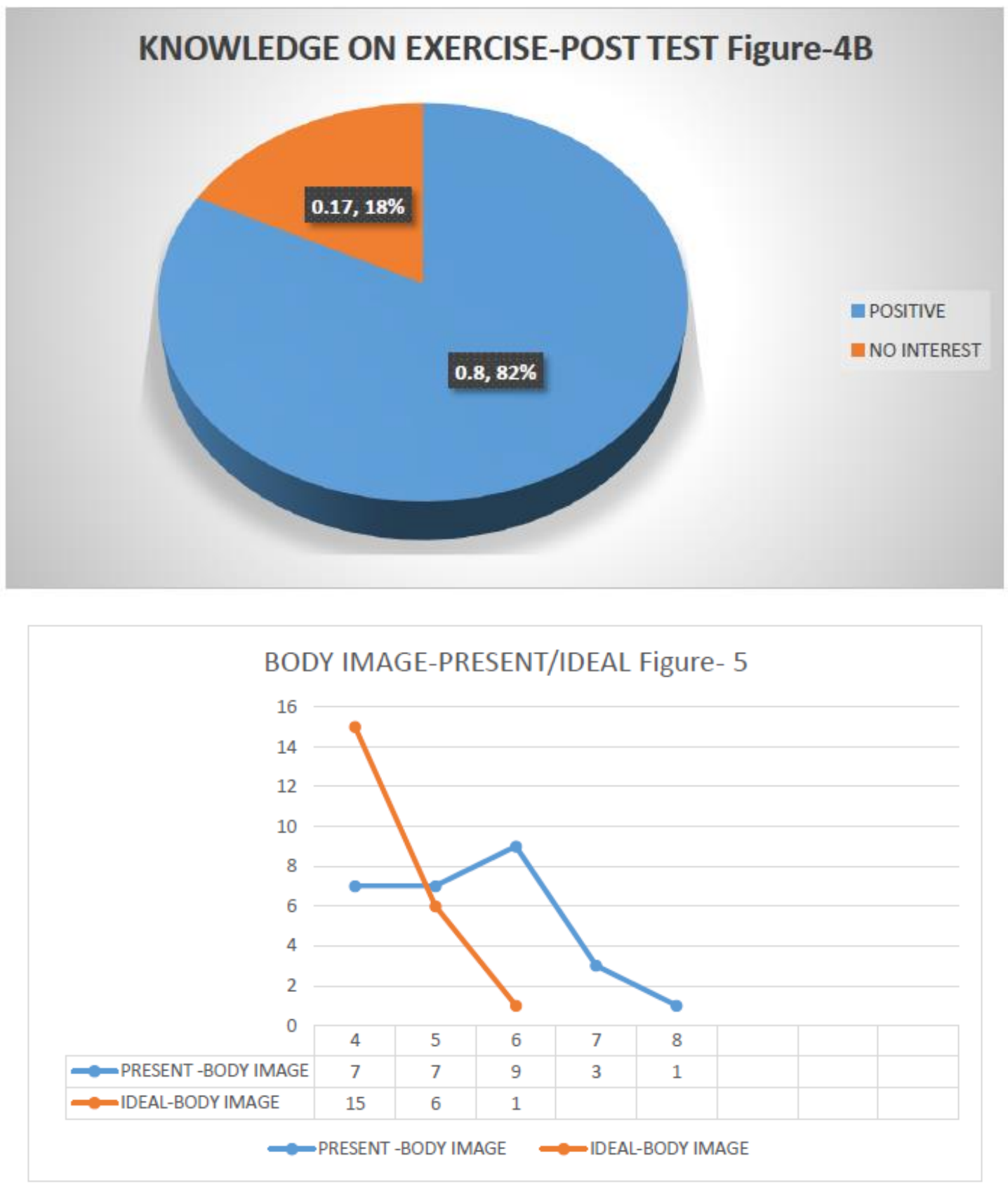


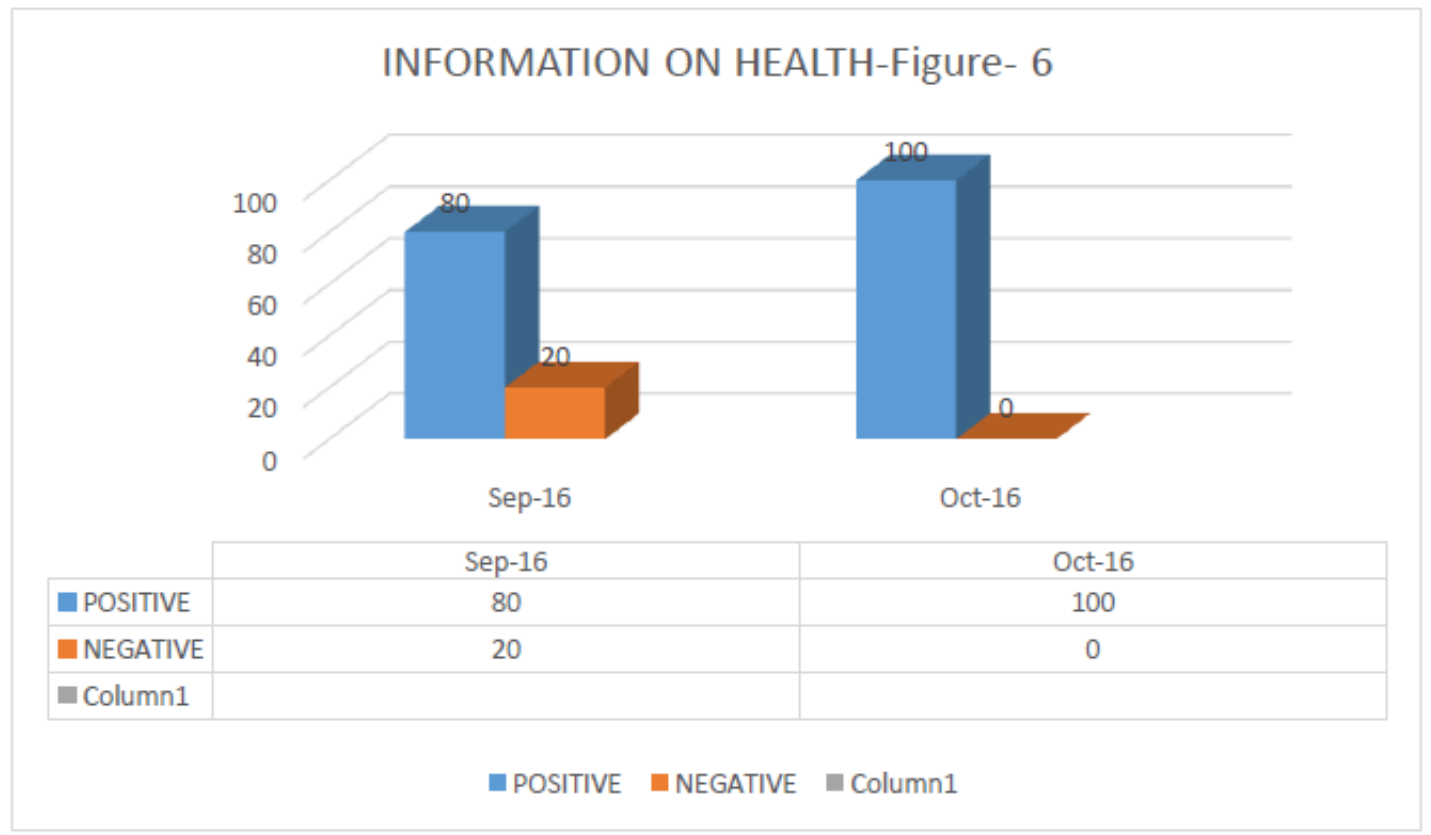

\section{Acknowledgment}

I acknowledge that this research is original, done on my own efforts, with my own ideas, knowledge and information. The content is true and reliable which is done on participant's approval.

\section{Reference}

[1]. A Study to Assess the Knowledge and Attitude of Adolescents on Obesity at Selected Senior Secondary Schools in Amritsar in a View to Develop and Distribute Information Booklet, International Journal of Education and applied research IJEAR Vol. 4, Issue 1, Jan - June 2014, ISSN: 2348-0033 (Online) ISSN: 2249-4944 (Print).

[2]. Obesity: preventing and managing the global epidemic. Report of a WHO Consultation. Geneva, World Health Organization, 2000 (WHO Technical Report; Series, No. 894).

[3]. Obesity-Related Knowledge, Attitudes, and Behaviors in Obese and Non-Obese Urban Philadelphia Female Adolescents, Department of Anthropology, University of Pennsylvania, Philadelphia, Pennsylvania. Address correspondence to Penny Gordon-Larsen, Department of Nutrition, University of North Carolina at Chapel Hill, Carolina Population Center, CB \#8120 University Square,123 West Franklin Street, Chapel Hill, NC 27516-3997.

E-mail: gordon_larsen@unc.edu Copyright @ 2001 NAASO. 